\title{
A TRADUÇÃO DA COMÉDIA ACARNENSES, DE ARISTÓFANES, POR ANA MARIA CÉSAR POMPEU
}

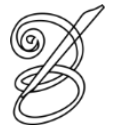 \\ Kall Lyws Barroso SALES \\ Universidade Federal de Santa Catarina
}

ARISTÓFANES. Acarnenses. Traduzido por: Ana Maria César Pompeu. In: POMPEU, Ana Maria César. Dioniso Matuto: uma abordagem antropológica do cômico na tradução de Acarnenses de Aristófanes para o cearensês. Editora Appris, Curitiba: 2014.

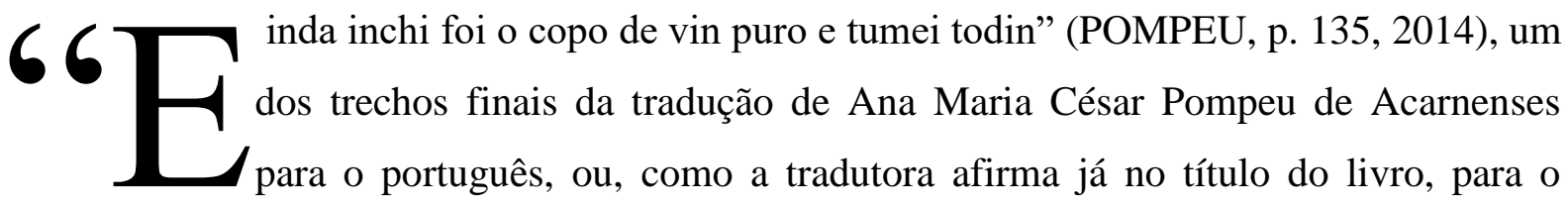
"cearensês", traz para a linguagem do matuto cearense um texto cômico grego. Assim, para compreender o sentido de se ler Aristófanes contemporaneamente, precisamos entender que a produção, reprodução e manutenção de seus textos são imprescindíveis para os estudos da tradução e da cultura grega, pois parte do que se conhece sobre as festividades helênicas só sobrevive pelos textos aristofânicos e suas traduções.

Sem dúvida, Aristófanes é mestre na arte cômica e não é à toa que é considerado o maior representante da comédia antiga. Essa afirmação ganha força ao se perceber que dele nos restaram onze comédias produzidas em Atenas durante os anos de 425 a.C, ano de apresentação da sua comédia mais antiga, e 388 a.C., data de apresentação da sua comédia mais recente. Muitos são os estudiosos que dedicaram parte da sua vida à pesquisa da obra de Aristófanes, bem como à produção de traduções de seus textos para inúmeras línguas estrangeiras. Com auxílio da plataforma da UNESCO, uma rápida pesquisa no Index Translationum mostra que temos o cadastro de trezentas traduções em diversas línguas das obras de Aristófanes. Em português, seu teatro conta com o trabalho de tradutores portugueses e brasileiros: António Lobo Vilela, que traduziu As aves (1984), As vespas (1984) e As aves (1990); Maria de Fátima de Sousa e Silva, que traduziu Os cavaleiros (1985), Acarnenses 
(1988), As mulheres que celebram as Tesmofórias (1988), As mulheres no parlamento (1988), A Paz (1989), As aves (1989), Pluto: a riqueza (1989) e Os Cavaleiros (1991). Também é expressivo o número de traduções em língua portuguesa realizadas pelos brasileiros: Américo Ramalho da Costa, que traduziu Pluto: a riqueza (1982) e Junito de Souza Brandão, que traduziu Ciclope, As rãs e As Vespas (1987).

Entretanto, esta listagem de obras traduzidas de Aristófanes não está completa, pois, no Brasil, contamos com, pelo menos, mais duas traduções de Aristófanes: Lisítrata (1998) e Acarnenses (2014), ambas realizadas por Ana Maria César Pompeu, professora de Língua e Literatura Gregas na Universidade Federal do Ceará. Das duas traduções de Acarnesnes em língua portuguesa, a de Ana Maria César Pompeu merece uma atenção especial, pois são inusitadas suas escolhas, já que o texto de Aristófanes foi traduzido não para uma variante corriqueira do português, mas para o "cearensês", como afirma a tradutora no título da publicação em que consta sua tradução.

A edição que apresenta a tradução é intitulada Dioniso Matuto: uma abordagem antropológica do cômico na tradução de Acarnenses de Aristófanes para o cearensês e se 302 configura não apenas pelo texto cômico traduzido, mas também por uma introdução à comédia aristofânica, à presença de Eurípedes na comédia de Aristófanes e à relação entre as falofórias gregas e a festa do pau de Santo Antônio do interior do Ceará. A edição também apresenta uma tradução de trechos da poética de Aristóteles que discorrem sobre a comédia e um estudo detalhado do processo tradutório para o "cearensês". Por isso, é notória a visibilidade da tradutora na publicação, já que o livro não apresenta apenas o texto cômico traduzido, mas também o decorrer da sua pesquisa antropológica e uma detalhada explicação ao leitor no que tange às escolhas de tradução. Suas explicações aparecem tanto nas paratraduções $^{\mathrm{ii}}$, apresentadas antes e depois da tradução da peça, quanto nas duzentas e vinte e três notas que acompanham o leitor durante a dramaturgia.

No livro, a tradutora renova e amplia um texto apresentado em 425 a.C, em Atenas, para uma linguagem na qual uma fonética artesanaliii busca representar o cômico no falar matuto. Quando necessária, há, na edição, a tradução dos nomes próprios, pois, com essa estratégia, o texto traduzido apresenta jogos de palavras que fazem com que os leitores entendam a ideia escondida no nome das personagens. Por exemplo, a personagem central da história é, em outras traduções para o português, chamada de "Diceópolis", transcrição clássica do nome grego. Todavia, para o leitor que desconhece a língua grega, o nome pode 
deixar imperceptível sua função dentro da peça. Assim, na tradução proposta por Pompeu, o nome "Diceópolis" se transforma em "Justinópolis" e, nas paratraduções de sua autoria, a tradutora expõe que o nome da personagem é formado por dois radicais gregos: dikaios, justo, e pólis, cidade. Se ela optasse por transliterar esse nome, o leitor poderia deixar passar uma ideia central à comédia: a personagem é a representante da paz, a que busca a reconciliação entre os gregos e, para alcançá-la, só sendo uma cidade justa, ou seja, Justinópolis.

Outro nome próprio que tem carga semântica representativa para a comédia é "Anfíteo", composto por outros dois radicais gregos: amphí, de um lado, e de outro, theós, deus. No texto de Pompeu, a personagem foi traduzida por "Ambídeus", única capaz de promover as tréguas entre espartanos e gregos, ou seja, aquela que se encontra de um lado e do outro na guerra.

Para além do jogo de palavras presente nos nomes das personagens, para os leitores do nordeste, em particular do Ceará, a leitura torna-se ainda mais interessante, porque a tradutora optou por fazer uma relação do texto grego como o falar típico e cararicatural do matuto do interior do Ceará. Essa característica marcadamente rural está representada nas falas de "Justinópolis" (Dikaiopolis), um homem do campo, e pela personagem Megarense, que representa a comédia megarense, mais antiga e rústica, e, portanto, na tradução, o falar mais marcado com a representação de sotaques evidentes na escrita.

Dessa forma, o texto grego se transforma em uma linguagem matuta que pode exigir do leitor uma repetição dos trechos para assim tentar compreender o que a personagem fala: "e eu meimo digo tumbém. Mar quem é burro axim, prá cumprá rôceis um prejuízo vizíve? Mar tenho meimo um artífiço megárico, Bacurinhas rô dizê qui trago disfaçando rôceis" (POMPEU, p.104, 2014). Como podemos perceber, essa fala da personagem tenta representar, na escrita, um falar da caricatura do matuto do Nordeste. Por isso, a primeira sensação que temos durante a leitura da tradução é que a peça precisa ser falada, pronunciada, para que possamos perceber tanto o efeito cômico do falar matuto, como entender o porquê da grafia dessa fonética artesanal da pronúncia do português para marcar uma oralidade matuta.

As marcas de oralidade são elemento ímpar na tradução, que conta com elementos de um falar que amplia a manifestação do português brasileiro escrito. Segundo a tradutora, os diálogos das personagens foram criados com inspiração no falar do homem do nordeste brasileiro, representado por comediantes da cidade Fortaleza, mas que tais pronúncias também são evidenciadas em outras regiões do Brasil (Ibid., p.59). Dessa forma, através da oralidade e 
das personagens matutas, nós, leitores contemporâneos, enxergamos a atualidade do texto da comédia antiga, texto que traz uma crítica à guerra, colocando a personagem que a defende em situação deplorável, como se percebe na fala da personagem Batalhão, vencida e derrotada: "Uma lança atravessou-me os ossos, que lamentável” (Ibid., p.134). Todavia, ao apresentar aqueles que buscam a paz e as tréguas, ou seja, Justinópolis, a comédia os glorifica e parabeniza como vencedores na voz do coro: "Mas vamo te segui pra te alegrá ó viv' ó vencedô, ó viv’o vencedô! Cantamos pra ti e pro odre" (Ibid., p.135, 2014). Assim, ao final da tradução do texto cômico, temos uma das cenas mais icônicas da peça, na qual a personagem que representa a guerra é apresentada ensanguentada, enquanto que o homem rural, que quer a paz, é apresentado nos braços da alegria, com vinho, ou o sangue transformado em alegria, dança, festejos falofóricos cheios de delícias para um homem do campo.

Esta exploração da linguagem escrita e falada através da tradução transforma o texto cômico grego e amplia a recepção da comédia de Aristófanes. Assim, com esta tradução, somos capazes de nos divertir com as cenas de confronto das personagens e de entender a necessidade da paz para o homem do campo, pois é este o que mais sofre com guerras e com conflitos que, para ele, são apenas destrutivos e não proporcionam nada de favorável.

RECEBIDO EM: 25 de setembro de 2017

ACEITO EM: 17 de novembro de 2017

PUBLICADO EM: dezembro de 2017

\footnotetext{
${ }^{\text {i }}$ Kall Lyws Barroso SALES. Doutorando e Mestre (2014) em Estudos da Tradução da Universidade Federal de Santa Catarina. Graduado em Letras Português-Francês (2009) pela Universidade Federal do Ceará. Graduado em Gestão de Sistemas Produtivos (2007) pela Faculdade de Tecnologia do Nordeste. Florianópolis, Santa Catarina, Brasil. O autor agradece à CAPES o financiamento referente à sua bolsa de doutorado sanduíche realizado na Université Bordeaux-Montaigne, França. Edital PDSE - Edital n ${ }^{\circ}$ 19/2016. Processo $n^{\circ}$ 88881.132949/2016-01.

Lattes: http://lattes.cnpq.br/6834884715432315 E-mail: kalllyws@gmail.com

ii Aqui uso o termo paratradução segundo a proposta de Yuste Frías em seu artigo Au seuil de la traduction: la paratraduction, de 2010.

iii Termo elaborado por Bucley no capítulo Oralité, distance sociale et universalité, do livro Oralité et Traduction, organizado por Michel Ballard em 2000.
} 